\title{
De invloed van seksuele oriëntatie op aandacht: een mogelijk gaydar- mechanisme ${ }^{1}$
}

Lorenza Colzato en Wery van den Wildenberg

Personen met een homoseksuele oriëntatie wordt vaak een 'telepathisch zesde zintuig' toegeschreven waarmee ze andere homoseksuelen zouden kunnen herkennen (Reuter, 2002). Dit fenomeen wordt ook wel aangeduid als gaydar - een samenstelling van gay en radar (Shelp, 2002). Ofschoon waarneembare verschillen tussen homo-en heteroseksuelen niet door iedereen worden opgemerkt, rapporteren verschillende studies subtiele maar onderscheidende kenmerken die worden gedeeld door homoseksuelen, zoals haardracht (Rule, Ambady, Adams Q Macrae, 2008), beweging van het lichaam en gebaren (Ambady, Hallahan a Connor, 1999), spraakpatroon (Linville, 1998), en grootte van de penis (Bogaert \& Hershberger, 1999). Er schijnt dus een perceptuele basis te zijn waarop mensen een betrouwbare gaydar kunnen ontwikkelen, en homoseksuelen zijn hier blijkbaar beter in getraind.

Deze studie gaat niet zozeer in op de individuele perceptuele-informatieelementen die ten grondslag liggen aan gaydar, maar beantwoordt de vraag of een homoseksuele oriëntatie is geassocieerd met systematische veranderingen in aandachtprocessen. De meeste perceptuele-infor-

\footnotetext{
Mw. dr. L.S. Colzato, psychologe, uhd, Universiteit Leiden, Departement Psychologie, Sectie Cognitieve Psychologie \& Leiden Institute for Brain and Cognition, Postbus 9555, 2300 RB Leiden, colzato@ fsw.leidenuniv.nl; dr. W.P.M. van den Wildenberg, neuropsycholoog, Universiteit van Amsterdam, Afdeling Psychologie.
}

matie-elementen die de gaydar moet verwerken, zijn relatief specifiek en lokaal van aard en vereisen dus gerichte aandacht om deze te snel te kunnen detecteren. Er is toenemend bewijs dat de gewoonte om bepaalde aandachtsets aan te wenden een chronische aandachtvoorkeur kan bewerkstelligen die generaliseert naar overige, niet-gerelateerde situaties.

Individuen die zijn opgegroeid in een Aziatische cultuur bijvoorbeeld, benaderen visuele scènes meer holistisch dan westerse individuen (Nisbett \& Masuda, 2003; Nisbett \& Miyamoto, 2005). Dit blijkt onder andere uit hun prestatie tijdens het verwerken van hiërarchische stimuli, zoals grote letters die bestaan uit kleinere letters, of grote geometrische figuren die zijn opgebouwd uit kleinere figuren. Mensen zijn geneigd om de globale dimensie sneller te verwerken dan de lokale dimensie. Dit fenomeen wordt aangeduid als 'globale voorrang' (Navon, I977, zie figuur I). Dit geldt voor zowel Aziatische als westerse culturen maar het globalevoorrangeffect is groter voor Aziaten dan voor NoordAmerikanen, wat wijst op een relatieve voorkeur voor details in de laatste groep. Dit verschil wordt verklaard in termen van cultureel leren; westerse mensen zijn opgevoed met een relatief onafhankelijk zelfbeeld, terwijl oosterse mensen zijn opgevoed met een sterkere nadruk op wederzijdse sociale afhankelijkheid (Markus \& Kitayama, I99I). Een sterker onafhankelijk dan wel afhankelijk zelfbeeld vereist wellicht een aandachtdispositie met een chronische voorkeur voor het verwerken van respectievelijk lokale dan wel globale eigenschappen van visuele stimuli (Hommel \& Colzato, in druk).

Recent onderzoek naar de invloed van religie op visuele aandacht bevestigt deze veronderstelling. Zo toonden Colzato, van den Wildenberg, en Hommel (2008) aan dat Nederlandse calvinisten en Nederlandse atheïsten (vergelijkbaar op het gebied van cul- 

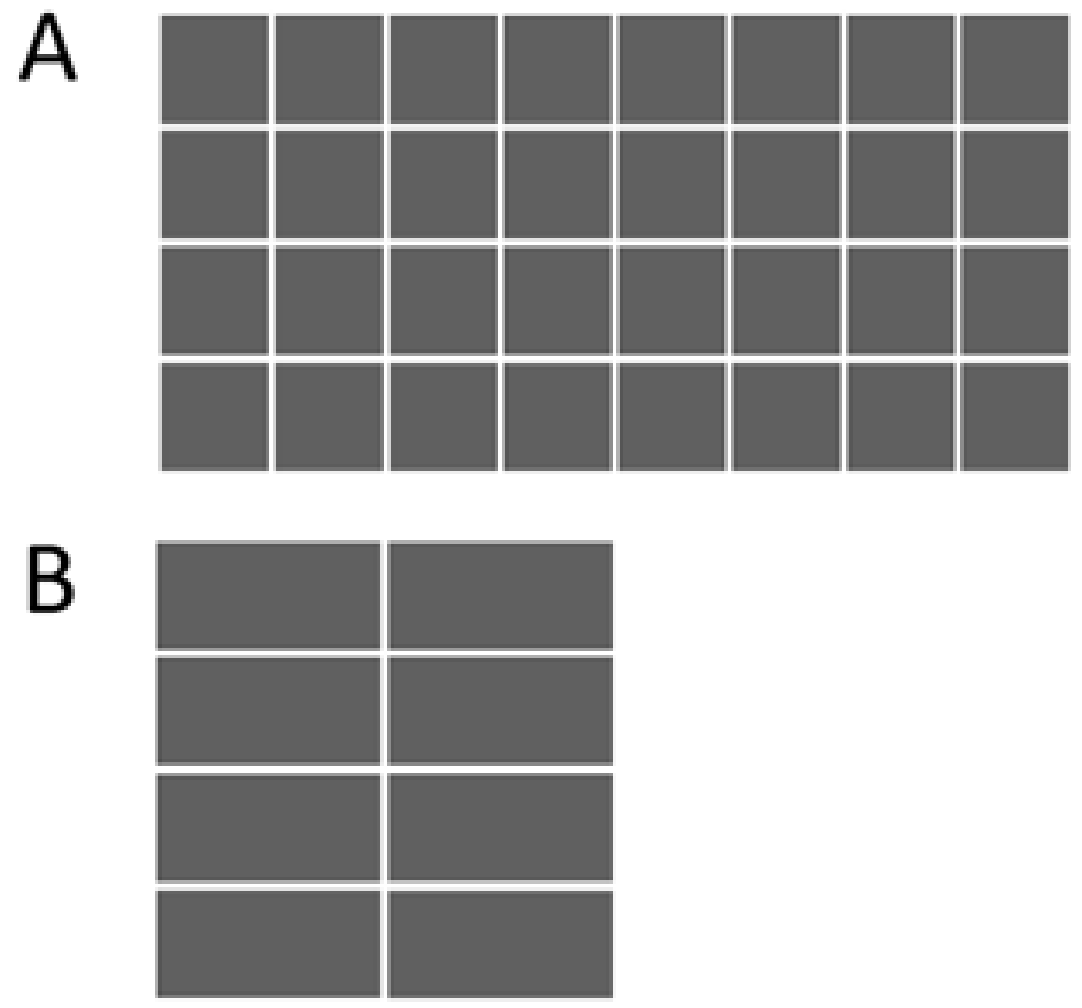

Figuur 1 A) Een grote rechthoek (globale stimulus) opgebouwd uit 32 kleine vierkanten (locale stimuli). B) Een groot vierkant (globale stimulus) opgebouwd uit acht kleine rechthoeken (locale stimuli). De globale dimensie wordt doorgaans eerder verwerkt dan de locale dimensie (d.w.z. globalevoorrangeffect).

tuur, etniciteit, geslacht, leeftijd en intelligentie) verschillen in het verwerken van globale en lokale visuele eigenschappen. Een van de steunpilaren van het neo-calvinisme is de soevereiniteit in eigen kring. Dat houdt kort gezegd in dat men niet dient te oordelen over andere groepen in de maatschappij maar dat elke groep zich met zijn eigen zaken bezighoudt. Dit doet vermoeden dat calvinisten een sterkere voorkeur hebben voor detail, en inderdaad, het globalevoorrangeffect is bij calvinisten kleiner dan bij atheisten. Recent onderzoek toont aan dat rooms-katholieken in Italië een groter globalevoorrangeffect laten zien dan Italiaanse seculieren en dat het globalevoorrangeffect tevens groter is voor Israëlische orthodoxe joden dan voor Israëlische niet-gelovigen (Colzato et al., 20Iо), wat overeenkomt met de sterke nadruk die zowel katholieken als orthodoxe joden leggen op sociale solidariteit en wederzijdse afhankelijkheid.

Genoemde bevindingen impliceren dat de manier waarop sociale/ culturele groepen het gedrag van hun leden vormen specifieke eisen stelt aan aandachtprocessen, hoogstwaarschijnlijk door middel van selectieve beloning van norm-conformistisch gedrag, (Colzato et al., 20Io; Hommel $\&$ Colzato, in druk). Deze specifieke eisen bevorderen bepaalde aandachtdisposities en creëren zo een chronische aandachtvoorkeur. Dit betekent niet noodzakelijkerwijs dat individuen het vermogen verliezen om de aandacht op andere aspecten te richten, maar dat dit relatief meer cognitieve inspanning vereist en zo ten koste gaat van hun prestatie. Als dit inderdaad het geval is, zou de gewoonte van homoseksuelen om zich te richten op lokale visuele eigenschappen kunnen leiden tot een gegeneraliseerde chronische aandachtvoorkeur voor het verwerken van lokale ten opzichte van globale aspecten. In dat geval zouden homoseksuelen een minder sterk globalevoorrangeffect laten zien dan heteroseksuelen bij de globaal-lokaaltaak (Navon, 1977). Wij hebben deze hypothese onderzocht bij mannen en vrouwen met een homo- of heteroseksuele oriëntatie.

\section{Methode}

\section{Deelnemers}

De steekproef bestond uit 42 gezonde deelnemers (25 mannen en I7 vrouwen) tussen I8 en 30 jaar. De helft van de proefpersonen had een heteroseksuele oriëntatie, de andere helft een homoseksuele oriëntatie. Deelnemers in deze twee groepen werden gematcht op etniciteit (Io०\% blank), cultuur (Io०\% Nederlands), leeftijd, geslacht en IQ (zoals gemeten door de Raven Matrix Test (Raven's Standard Progressive Matrices), religieuze achtergrond, opleiding (VWO) en sociaaleconomische status (zie tabel I en 2). Deelnemers werden geworven door middel van advertenties en mond-tot-mondreclame. Deelnemers gaven schriftelijk toestemming nadat het doel van het onderzoek was uitgelegd; het protocol en de betaling van acht euro werd goedgekeurd door de lokale Commissie Ethiek (Universiteit Leiden, Instituut voor Psychologisch Onderzoek).

\section{Apparatuur en stimuli}

Proefpersonen reageerden door het indrukken van de ' $z$ '- of de '?'-toets op een QWERTY-toetsenbord met res- 
Tabel 1 Demografische gegevens van deelnemers.

Homoseksuelen Heteroseksuelen

\begin{tabular}{|c|c|c|}
\hline geslacht $\mathrm{N}(\mathrm{M}: \mathrm{V})^{\mathrm{ns}}$ & $21 \quad(13: 8)$ & $21 \quad(12: 9)$ \\
\hline leeftijd (jaren) ${ }^{\mathrm{ns}}$ & $22,0 \quad(2,12)$ & $20,9 \quad(2,68)$ \\
\hline Raven IQ ${ }^{\text {ns }}$ & $124,5 \quad(3,10)$ & $125,0 \quad(4,27)$ \\
\hline \multicolumn{3}{|l|}{ affect } \\
\hline opwindingns & $5,43(1,60)$ & $5,48(1,36)$ \\
\hline stemming $^{\text {ns }}$ & $6,29(1,15)$ & $6,62(1,16)$ \\
\hline \multicolumn{3}{|l|}{ persoonlijkheid } \\
\hline extraversie ${ }^{\text {ns }}$ & $10,43(1,94)$ & $8,95(3,23)$ \\
\hline psychoticisme $^{\text {ns }}$ & $3,53(1,89)$ & $3,10(1,64)$ \\
\hline neuroticisme ${ }^{\text {ns }}$ & $4,10(2,76)$ & $4,52(2,68)$ \\
\hline
\end{tabular}

Standaarddeviaties tussen haakjes

${ }^{n s}$ niet-significant verschil

pectievelijk de linker en rechter wijsvinger. De stimuli zijn overgenomen uit Huizinga, Dolan en Van der Molen (2006), en bestonden uit geometrische figuren: grote (globale) rechthoeken of vierkanten die zijn opgebouwd uit kleine (lokale) rechthoeken of vierkanten. Globale stimuli (vierkanten of rechthoeken; respectievelijk $93 \times 93$ pixels of $93 \times$ I 89 pixels) bestonden uit meerdere lokale stimuli (vierkanten of rechthoeken; respectievelijk 2I x 2I pixels of $8 \times 46$ pixels). De ruimte tussen de lokale elementen was drie pixels. Een globaal vierkant bestond uit I6 kleine vierkanten of acht kleine rechthoeken; een globale rechthoek bestond uit 32 kleine vierkanten of $\mathrm{I} 6$ kleine rechthoeken (zie figuur I).

\section{Procedure en opzet}

Alle deelnemers werden individueel getest en voltooiden de intelligentietest, de affectvragenlijst, en Eysenck Personality Questionnaire (EPQ-RSS), de seksuele-oriëntatievragenlijst en de globaal-lokaaltaak.

IQ werd gemeten door een 30-minuten durende intelligentietest (Raven's Standard Progressive Matrices: SPM (Raven, Court \& Raven, I988).
De SPM meet het vermogen om perceptuele verbanden te leggen en meet analogisch redeneren ongeacht taal- en opleidingsniveau. Het is een veelgebruikte standaardtest om Spearmans g te meten, met name 'vloeiende intelligentie'.

De affectvragenlijst bestaat uit een één-item-schaal die affect meet op de dimensies onplezierig/plezierig gevoel en opwinding/slaperigheid (Russell, Weiss \& Mendelsohn, I989). Het affectraster is gebruikt om te controleren voor stemming, omdat eerder is aangetoond dat stemming van invloed is op aandacht. Zo leidt een positieve stemming tot een meer globale aandacht (Rowe, Hirsh \& Anderson, 2007). Deelnemers werd gevraagd om een markering aan te brengen in het raster om hun gevoel op het moment aan te geven. De verticale dimensie representeerde de mate van opwinding versus slaperigheid, de horizontale dimensie representeerde onplezierige versus plezierige gevoelens.

De EPQ-RSS-vragenlijst bestaat uit 48 ja/nee-vragen die extraversie-, neuroticisme- en psychoticismetendensen van de persoonlijkheid meten
(Eysenck, Eysenck \& Barrett, I985). We hebben gecontroleerd voor persoonlijkheidseigenschappen omdat meer extraverte individuen een ruimer blikveld hebben vergeleken met meer neurotische individuen (Kossowska \& Necka, I994).

De Nederlandse vertaling van het seksuele-oriëntatieraster (Klein, Sepekoff \& Wolf, I985) is gebruikt om seksuele voorkeur te kwantificeren. Deze schaal bestaat uit zeven variabelen die de seksuele oriëntatie van een persoon aangeven op drie verschillende gebieden: het verleden, het heden en het ideaal. Deelnemers scoren elk van de 2 I resulterende combinaties op een 7-puntsschaal van I (= alleen het andere geslacht) tot 7 (= alleen hetzelfde geslacht), voor de variabelen seksuele aantrekking, seksueel gedrag, seksuele fantasieën, emotionele voorkeur en sociale voorkeur. Voor de variabelen life-style en zelfidentificatie varieert de schaal van I (= alleen heteroseksueel) tot 7 (= alleen homo/lesbisch).

Tijdens het uitvoeren van de globaal-lokaaltaak (vgl. Huizinga et al., 2006) reageerden deelnemers op willekeurig gepresenteerde rechthoeken of vierkanten door respectievelijk op de linker- of rechterknop te drukken. Een visuele aanwijzing gaf aan op welke dimensie (globaal of lokaal) gereageerd moest worden. Aanwijzingen voor de globale dimensie bestonden uit een groot vierkant gepresenteerd aan één kant van de stimulus en een grote rechthoek gepresenteerd aan de andere zijde. Aanwijzingen voor de lokale dimensie bestonden uit een klein vierkant, gepresenteerd aan één kant van de stimulus, en een kleine rechthoek, gepresenteerd aan de andere kant van de stimulus. De kleur van de aanwijzingen en stimuli was rood en deze bleven op het scherm tot een knop was ingedrukt of $3500 \mathrm{~ms}$ waren verstreken. Het tijdsinterval 
tussen de presentatie van de aanwijzing en de stimulus was $500 \mathrm{~ms}$; het interval tussen een respons en de presentatie van de volgende aanwijzing was Ioo० ms. Deelnemers reageerden op de globale vorm in één oefenblok en op de lokale vorm in een ander oefenblok. De volgorde van deze oefenblokken was willekeurig en elk blok bestond uit 50 trials. In het derde, experimentele, blok reageerden de deelnemers op voorspelbare reeksen van vier lokale en vier globale trials.
Statistische analyse

Groepsverschillen in leeftijd, stemming, persoonlijkheidstendensen en IQ werden onderzocht met behulp van t-toetsen. Net als Colzato et al. (2008) en Huizinga et al. (2006) werden de medianen van de reactietijden en de wortel van de foutpercentages geanalyseerd met behulp van ANOVA's, met Dimensie (globaal vs. lokaal) als binnen-proefpersoonfactor en Groep (homoseksueel vs. heteroseksueel) als tussen-proefpersoon-

Tabel 2 Gemiddelde scores op de seksuele-oriëntatie vragenlijst op een 7-puntsschaal.

Schaal Homoseksuelen Heteroseksuelen

\begin{tabular}{|c|c|c|}
\hline seksuele aantre & & \\
\hline ideaal"kt & $6,48(0,81)$ & $1,10(0,31)$ \\
\hline heden ** & $6,38(0,59)$ & $1,15(0,37)$ \\
\hline verleden $n^{* * x}$ & $4,71 \quad(1,35)$ & $1,10(0,31)$ \\
\hline seksueel gedrag & & \\
\hline ideaal ${ }^{* *}$ & $6,48(0,68)$ & $1,05(0,22)$ \\
\hline heden ${ }^{* *}$ & $6,52(0,81)$ & $1,00(0,00)$ \\
\hline verleden & $4,95(2,25)$ & $1,05(0,22)$ \\
\hline seksuele fantasiee & & \\
\hline ideaal $^{\text {*k }}$ & $6,29(0,90)$ & $1,25(0,64)$ \\
\hline heden ** & $6,33(0,91)$ & $1,25(0,64)$ \\
\hline verleden ${ }^{* \star * x}$ & $5,57(1,63)$ & $1,15(0,49)$ \\
\hline emotionele voork & & \\
\hline ideaal $^{* *}$ & $6,05(1,16)$ & $1,15(0,37)$ \\
\hline heden ${ }^{\text {*h }}$ & $5,71 \quad(1,15)$ & $1,15(0,37)$ \\
\hline verleden ${ }^{* \star *}$ & $4,43(1,57)$ & $1,15(0,37)$ \\
\hline life-style & & \\
\hline ideaal $^{* *}$ & $4,00(0,84)$ & $2,45(1,00)$ \\
\hline heden ** & $3,81 \quad(1,60)$ & $1,95(0,76)$ \\
\hline verleden ${ }^{\text {*k* }}$ & $2,52(1,60)$ & $1,70(0,86)$ \\
\hline zelfidentificatie & & \\
\hline ideaal $^{* * k}$ & $6,51 \quad(0,75)$ & $1,15(0,37)$ \\
\hline heden ** & $6,29(0,64)$ & $1,15(0,37)$ \\
\hline verleden ${ }^{\text {*kx }}$ & $4,14(1,80)$ & $1,10(0,31)$ \\
\hline sociale voorkeur & & \\
\hline ideaal $^{\text {ns }}$ & $4,48(0,75)$ & $4,00(1,12)$ \\
\hline heden $^{\text {ns }}$ & $4,51 \quad(1,24)$ & $4,25(1,16)$ \\
\hline verleden $^{\text {ns }}$ & $4,48(1,33)$ & $4,10(1,89)$ \\
\hline
\end{tabular}

Standaardfouten tussen haakjes.

${ }^{n s}$ niet-significant verschil; ${ }^{* *}$ significant groepsverschil, $p<0.01$.

factor. Voor alle toetsen werd een significantieniveau aangehouden van $p<0,05$.

\section{Resultaten}

\section{Seksuele-oriëntatievragenlijst}

Analyse van de antwoorden op het seksuele-oriëntatieraster (Klein et al., I985) liet een significant verschil zien tussen homo- en heteroseksuelen op de variabelen seksuele aantrekking, seksueel gedrag, seksuele fantasieën, emotionele voorkeur, life-style en zelfidentificatie. Alle variabelen hebben betrekking op het verleden (meer dan anderhalf jaar geleden), het heden, en de ideale situatie. Er werden geen significant groepsverschillen gevonden op sociale voorkeur voor het verleden $\mathrm{t}(40)=0,92, \mathrm{p}=0,36$, heden, $\mathrm{t}(40)$ $=0,73, p=0,47$, en ideale situatie, $\mathrm{t}(40)=\mathrm{I}, 60, \mathrm{p}=\mathrm{O}, \mathrm{I} 2$. De schaal sociale voorkeur heeft betrekking op het geslacht van de mensen met wie de deelnemer omgaat. Het is daarom niet verrassend dat deze variabele geen significant verschil laat zien tussen homo- en heteroseksuelen (zie tabel 2 voor een overzicht).

\section{Globaal-lokaaltaak}

Heteroseksuelen reageerden over het algemeen genomen iets sneller maar minder nauwkeurig dan homoseksuelen, maar na toetsing bleken reactietijden en foutpercentages niet significant te verschillen tussen de twee groepen, ps > 0.25. Analyse van reactietijden laat een hoofdeffect zien voor Dimensie, $\mathrm{F}(\mathrm{I}, 40)=89,45, \mathrm{p}<$ $0.0001, \mathrm{MSE}=674,69, \eta 2 \mathrm{p}=0.69$, in overeenstemming met het globalevoorrangeffect waarbij sneller wordt gereageerd op globale dan op lokale stimuli (Navon, I977) . Zoals verwacht verschilde dit effect per Groep, F(I, 40) $=6, \mathrm{I7}, \mathrm{p}<0.05, \mathrm{MSE}=674.69$, $\eta 2 p=0.13$, (zie figuur 2). Homosek- 
Tabel 3 Gemiddelde reactietijden ( $R T$, in $\mathrm{ms}$ ) en foutpercentages (fout, in \%) voor reacties op globale en lokale stimuli en het globalevoorrangeffect (lokaal minus globaal).

\section{Homoseksuelen}

RT

globale stimuli

lokale stimuli

globale voorrang

Heteroseksuelen

\section{$R T$}

$350(44)$

$418(60)$

$68^{\text {** }}$ fouten

$5,1(3,8)$

$454(64)$

$40^{\text {** }}$

$7,8(6,8)$

2,5
$11,2(7,3)$

6,1

Standaardfouten tussen haakjes; *** significante groepsverschillen; $p<0.01$

suelen lieten een minder groot, maar nog steeds significant, $\mathrm{F}(\mathrm{I}, 2 \mathrm{O})=2 \mathrm{I}, \mathrm{I} 4$, $\mathrm{p}<0.00 \mathrm{I}, \mathrm{MSE}=775,68, \eta 2 \mathrm{p}=0.5 \mathrm{I}$, globalevoorrangeffect zien dan heteroseksuelen, $\mathrm{F}(\mathrm{I}, 20)=83,9, \mathrm{p}<0.000 \mathrm{I}$, $\mathrm{MSE}=573,4 \mathrm{I}, \eta 2 \mathrm{p}=0.8 \mathrm{I}$, (z.ie tabel 3). Analyse van de fouten liet ook een hoofdeffect zien voor Dimensie, F(I, 40) $=\mathrm{I} 2,93, \mathrm{p}<0.0 \mathrm{I}, \mathrm{MSE}=30,23$, $\eta 2 \mathrm{p}=0,23$. Er werden meer fouten gemaakt op lokale stimuli, maar dit effect werd niet gemodereerd door Groep.

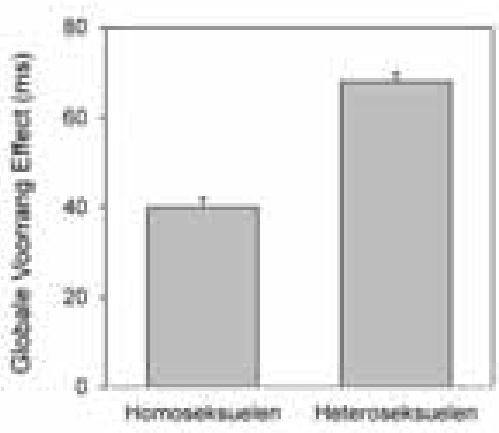

Figuur 2 Het globalevoorrangeffect voor homoseksuelen is kleiner vergeleken met heteroseksuelen. Verticale lijnen op de balken geven standaardfouten van het gemiddelde aan.

\section{Discussie}

Het doel van deze studie was te onderzoeken of de seksuele voorkeur van mensen samenhangt met een gegeneraliseerde aandachtvoorkeur voor het verwerken van lokale perceptueleinformatie-elementen. Over het algemeen reageerden deelnemers sneller op globale dan op lokale eigenschappen van visuele stimuli; een replicatie van het globalevoorrangeffect (Navon, I977). Zoals voorspeld werd dit effect beïnvloed door seksuele voorkeur: homoseksuelen lieten een minder sterk globalevoorrangeffect zien dan heteroseksuelen, hetgeen suggereert dat homoseksuelen inderdaad een meer analytische (lokale) perceptiestijl hebben.

Het aanwenden van een dergelijke perceptiestijl vergroot waarschijnlijk de kans op het waarnemen van perceptuele-informatie-elementen die samenhangen met een homoseksuele oriëntatie, wat het makkelijker maakt om gelijkgestemden en potentiële vrienden en seksuele partners te vinden. Dus, het aannemen van een lokale aandachtset wordt waarschijnlijk sociaal bekrachtigd, hetgeen er blijkbaar toe leidt dat deze aandachtset dermate wordt ingeprent dat deze generaliseert naar overige, nietsociale situaties, zoals het reageren op geometrische figuren. Overeenkomstig onze hypothese lieten Ambady et al. (I999) zien dat homoseksuelen beter zijn dan heteroseksuelen in het herkennen van de seksuele voorkeur van anderen op foto's en in korte videoclips. Gezien het feit dat homoseksuelen niet beter presteerden dan heteroseksuelen wanneer de videoclips langere tijd werden getoond, is het niet waarschijnlijk dat zij een betere kennis hebben over perceptuele-informatie-elementen die samenhangen met seksuele oriëntatie. Het lijkt er eerder op dat zij beter (sneller en/of efficiënter) zijn in het detecteren van deze informatie-elementen in de visuele omgeving. Onze bevindingen wijzen erop dat dit komt omdat hun aandachtset beter is afgestemd om deze lokaal gedefinieerde informatie elementen op te pikken. Het is echter nog niet duidelijk of deze locale aandachtvoorkeur voldoende is voor het ontwikkelen van een betrouwbare gaydar.

Wij speculeren dat homoseksuelen eerder geneigd zijn om een chronische lokale-aandachtset aan te nemen omdat deze de verwerking van gedragsrelevante informatie elementen faciliteert, en dus beloond wordt. Een alternatieve interpretatie zou kunnen samenhangen met de sociale situatie waarin homoseksuelen zich bevinden (Derryberry \& Reed, I998). Gezien het feit dat homoseksuelen een minderheid zijn binnen onze samenleving, zou het homo zijn kunnen samenhangen met een verhoogde mate van angst - een affectieve toestand die samenhangt met een vernauwde aandacht (Rowe et al., 2007). Ook worden homoseksuelen tijdens hun leven vaker geconfronteerd met discriminatie dan heteroseksuelen (Mays \& Cochran, 200I) en het is aannemelijk dat dit zorgt voor een verhoogde psychologische druk bij homoseksuelen (Meyer, I995). Zo lijken homoseksuele mannen inderdaad angstiger in sociale interacties dan heteroseksuele mannen, wat mogelijk wordt veroorzaakt door eerdere ervaringen met stigmatisering en discriminatie (Pachankis \& Goldfried, 2006). Wij hebben echter geen aanwijzingen voor grotere angst of opwinding gevonden bij de homoseksuele deelnemers aan onze studie: de twee groepen verschilden op geen enkele schaal van affectieve staat of persoonlijkheid, en de numerieke waarden lieten 
eerder lagere dan hogere scores voor neuroticisme en opwinding zien voor homoseksuelen. Ofschoon deze bevindingen niet in tegenspraak zijn met eerdere resultaten dat homoseksuelen meer sociale angst ervaren, sluiten ze wel een stressgerelateerde oorzaak van de lokale-aandachtvoorkeur uit.

Vanuit een breder perspectief dragen onze bevindingen bij aan eerdere observaties dat het lidmaatschap van een sociale groep vorm geeft aan specifieke cognitieve controle processen. Deze groep kan gebaseerd zijn op een gedeelde cultuur (Boduroglu et al., 2009; Nisbett \& Masuda, 2003; Nisbett \& Miyamoto, 2005), religie (Col- zato et al., 2008; Colzato et al., 2010) of, zoals dit onderzoek laat zien, een gedeelde seksuele oriëntatie. Ofschoon meer onderzoek nodig is naar de condities en processen, lijkt het aannemelijk dat sociale groepen uitingen van bepaald gedrag selectief belonen. Dit suggereert, impliceert of vereist het gebruik van bepaalde cognitieve sets of controle strategieën (Colzato et al., 20Iо; Hommel \& Colzato, in druk). Zodra een strategie of set voldoende is bekrachtigd, kan deze generaliseren naar andere, niet-gerelateerde situaties, en zo de informatieverwerking in bredere zin beïnvloeden. Er zijn geen redenen om aan te nemen dat dit scenario zich beperkt tot cultuur, religie en seksuele oriëntatie, wat duidt op een algemeen mechanisme. Deze visie sluit aan bij Nisbett en Miyamoto (2005) die impliceren dat iedere vorm van sociaal gestuurd gedrag de potentie heeft om te leiden tot een systematische cognitieve voorkeur.

\footnotetext{
Noot

1. Dit artikel is de vertaling van Colzato, L.S., van Hooidonk, L., van den Wildenberg, W.P.M., Harinck, F. and Hommel, B. (2010) Sexual orientation biases attentional control: A possible gaydar mechanism. Frontiers in Psychology, 1,13. doi: 10.3389/ fpsyg.2010.00013.
}

\section{Literatuur}

Ambady, N., Hallahan, M. \& Conner, B. (1999). Accuracy of judgments of sexual orientation from thin slices of behavior. Journal of Personality and Social Psychology, 77, 538-547.

Boduroglu, A., Shah, P. \& Nisbett, R.E. (2009). Cultural differences in allocation of attention in visual information processing. Journal of Cross-Cultural Psychology, 40, 349-360.

Bogaert, A.F. \& Hershberger, S. (1999). The relation between sexual orientation and penile size. Archives of Sexual Behavior, 28, 213-221.

Colzato, L.S., Wildenberg, W.P.M. van den \& Hommel, B. (2008). Losing the big picture: How religion may control visual attention, PLOS ONE, 3, e3679.

Colzato, L.S., Wildenberg, W.P.M. van den, Scorolli, C., Borghi, A.M., Dorchin, S., Meiran, N. \& Hommel, B. (in druk). Religious control of visual attention: Evidence from Neo-Calvinism, Roman Catholicism, and Orthodox Judaism. Cognition.

Derryberry, D. \& Reed, M.A. (1998). Anxiety and attentional focusing: Trait, state and hemispheric influences. Personality and Individual Differences, 25, 745-761.

Eysenck, S.B.G., Eysenck, H.J. \& Barrett, P. (1985). A revised version of the psychoticism scale. Personality and Individual Differences, 6, 21-29.

Hommel, B. \& Colzato, L.S. (in druk). Religion as a control guide: on the impact of religion on cognition. Zygon: Journal of Religion a Science.

Huizinga, M., Dolan, C.V. \& Molen, M.W van der (2006). Age-related change in executive function: Developmental trends and a latent variables analysis. Neuropsychologia, 44, 2017-2036.

Klein, F., Sepekoff, B. \& Wolf, T.J. (1985). Sexual orientation: A multivariable dynamic process. Journal of Homosexuality, 11, 35-49.

Kossowksa, M. \& Necka, E. (1994). Do it your own way: Cognitive strategies, intelligence, and personality. Personality and Individual Differences, 16, 33-46.

Linville, S. (1998). Acoustic correlates of perceived versus actual sexual orientation in men's speech. Pholia Phoniatrica et Logopaedica, 50 , 35-48.

Markus, H.R. \& Kitayama, S. (1991). Culture and the self: Implications for cognition, emotion, and motivation. Psychological Review, 98, 224-253.

Mays, V.M. \& Cochran, S.D. (2001). Mental health correlates of perceived discrimination among lesbian, gay, and bisexual adults in the United States. American Journal of Public Health, 91, 1869-1876.

Meyer, I.H. (1995). Minority stress and mental health in gay men. Journal of Health and Social Behavior, 36, 38-56.

Navon, D. (1977). Forest before trees: The precedence of global features in visual perception. Cognitive Psychology, 9, 353-383.

Nisbett, R.E. \& Masuda, T. (2003). Culture and point of view. Proceedings of the National Academy of Sciences, 100, 11163-11170.

Nisbett, R.E. \& Miyamoto, Y. (2005). The influence of culture: Holistic versus analytic perception. Trends in Cognitive Sciences, 9, 467-473.

Pachankis, J.E. \& Goldfried, M.R. (2006). Social anxiety in young gay men. Anxiety Disorders, 20, 996-1015.

Raven, J.C., Court, J.H. \& Raven, J. (1988). Manual for Raven's progressive matrices and vocabulary scales. London: Lewis.

Reuter, D.F. (2002). Gaydar: The ultimate insider guide to the gay sixth sense. New York: Crown.

Rowe, G., Hirsh, J.B. \& Anderson, A.K. (2007). Positive affect increases the breath of attentional selection. Proceedings of the National Academy of Sciences of the United Stated of America, 104, 383-388.

Rule, N.O., Ambady, N., Adams Jr., R.B. \& Macrae, C.N. (2008). Accuracy and awareness in the perception and categorization of male sexual orientation. Journal of Personality and Social Psychology, 95, 1019-1028.

Russell, J.A., Weiss, A. \& Mendelsohn, G.A. (1989). Affect grid: A singleitem scale of pleasure and arousal. Journal of Personality and Social Psychology, 57, 493-502.

Shelp, S.G. (2002). Gaydar: Visual detection of sexual orientation among gay and straight men. Journal of Homosexuality, 44, 1-14. 